\title{
Haematological, Oxidative Stress and Trace Elements Variations Associated with Emaciation in Pre-Slaughter White Fulani Cows
}

Funmilola Clara Thomas ( $\nabla$ thomasfc@funaab.edu.ng )

Federal University of Agriculture Abeokuta https://orcid.org/0000-0002-1052-222X

Richard Edem Antia

University of Ibadan

Fakilahyel Mshelbwala

Federal University of Agriculture

Eyitayo Solomon Ajibola

Federal University of Agriculture Abeokuta

Obokparo Godspower Ohore

University of Ibadan

Samson Adisa Rahman

Federal University of Agriculture Abeokuta

Abdulhafiz Oloruntoba Ayanleye

Federal University of Agriculture Abeokuta

\section{Research Article}

Keywords: Anemia, Antioxidants, Cattle, Emaciation, Malondialdehyde

Posted Date: September 16th, 2021

DOI: https://doi.org/10.21203/rs.3.rs-776309/v1

License: (c) (1) This work is licensed under a Creative Commons Attribution 4.0 International License.

Read Full License 
1 Haematological, oxidative stress and trace elements variations associated with emaciation in

2 pre-slaughter White Fulani cows

3 Funmilola Clara Thomas.., Richard Edem Antia. ${ }^{2}$, Fakilahyel Mshelbwala ${ }^{3}$, Eyitayo Solomon

4 Ajibola $^{1}$, Obokparo Godspower Ohore $^{2}$, Samson Adisa Rahman ${ }^{1}$, Abdulhafiz Oloruntoba 5 Ayanleye 1.

$7 \quad{ }^{1}$ Department of Veterinary Physiology and Biochemistry, College of Veterinary Medicine, Federal

8 University of Agriculture, Abeokuta

$9 \quad{ }^{2}$ Department of Veterinary Pathology, Faculty of Veterinary Medicine, University of Ibadan

$10{ }^{3}$ Department of Veterinary Pathology, College of Veterinary Medicine, Federal University of 11 Agriculture, Abeokuta

$12{ }^{*}$ Corresponding Author: Department of Veterinary Physiology and Biochemistry, College of

13 Veterinary Medicine, Federal University of Agriculture, Abeokuta

14 Email; thomasfc@ funaab.edu.ng

15 Phone: +2348181962523 


\section{Abstract}

18 Pre-slaughter White Fulani cows were purposively sampled on the basis of body condition:

19 emaciated $(n=37)$ and non-emaciated $(n=37)$, with the objective of understanding the intricate

20 interplay of oxidative stress, trace elements and haematological variations during emaciation.

21 Blood was drawn from the jugular vein for haematological analysis and accruing serum was used

22 for the evaluation of malondialdehyde (oxidative stress marker), antioxidant enzymes and

23 compounds, serum protein, electrolytes as well as trace elements. Significant $(\mathrm{p}<0.05)$ differences

24 between the emaciated and non-emaciated cows were established only in the values of copper and

25 reduced glutathione (GSH), which were lower in emaciated cows (EC). None of the animals had

26 packed cell volume (PCV) below the normal reference range, however values above the normal

$27(>46 \%)$ were seen, suggesting dehydration. The PCV in emaciated cattle was slightly lower than

28 in non-emaciated cows. The mean malondialdehyde concentration in non-emaciated cattle was

29 higher than that in emaciated ones, however antioxidants SOD, catalase, Vitamin C and zinc were

30 slightly higher in non-emaciated cows (NEC). Overall, the results indicate that emaciation in

31 studied White Fulani cows (WFC) displayed a variable redox homeostasis confounded by 32 dehydration and depletion of antioxidants.

33

34 Keywords: Anemia, Antioxidants, Cattle, Emaciation, Malondialdehyde 


\section{Declarations}

36 Funding; The authors did not receive support from any organization for the submitted work. The authors have no relevant financial or non-financial interests to disclose

42 Availability of data and material: The datasets generated during and/or analyzed during the

43 current study are available from the corresponding author on reasonable request.

45 Code availability:

46 Not applicable

\section{Authors' contributions:}

50 All authors contributed to the study. Conception and design were done by [Richard Edem Antia] 51 and [Obokparo Godspower Ohore]. Material preparation, data collection and analysis were 52 performed by [Funmilola Clara Thomas], [Abdulhafiz Oloruntoba Ayanleye], [Eyitayo Solomon 53 Ajibola] and [Samson Adisa Rahman]. The first draft of the manuscript was written by [Funmilola

54 Clara Thomas] and [Fakilahyel Musa Mshelbwala] improved on previous versions of the 55 manuscript. All authors read and approved the final manuscript.

59 The ethics governing the use and conduct of experiments on animals were strictly observed, and

60 the experimental protocol was approved by the College of Veterinary Medicine, Federal University

61 of Agriculture, Abeokuta Research Ethics Committee (CREC). The necessary permissions and 
62 consent were obtained from the Abattoir management under the Ogun State Ministry of

63 Agriculture and Natural resources, Veterinary Services Divisions, before collection of data and 64 blood from pre-slaughter cattle at the Lafenwa abattoir, Abeokuta.

66 Consent to participate:

67 Verbal informed consent was obtained prior to use of all animals for the study; including the

68 collection of data and sampling of cattle brought in by individuals to the abattoir.

69

70 Consent to publish:

71 Not applicable

72

73 Statement of animal rights:

74 The study was performed in accordance with the ethical standards as laid down in the 1964

75 Declaration of Helsinki and its later amendments.

76

77 Conflicts of interest/Competing interests:

78 The authors declare that no competing interests exists. 
81 Emaciation is a common pathological condition marked by a depreciation of body condition

82 occasioned by the loss of fat and muscle, diminution of organ size and sometimes edematous

83 effusions sequel to anorexia, starvation or cachexia. It is a leading cause of carcass condemnation

84 at ante- and post mortem meat inspection (Kambarage et al., 1995; Phiri, 2006; Raji et al., 2010)

85 and contributes largely to under-pricing and rejection of carcasses for use as meat (due to

86 organoleptic changes in meat (Pełczyńska, 1987). Significant losses also accrue in other consumer

87 products, at critical points of the beef or diary production value chain due to weight loss (Mesele

88 et al., 2012; Assefa and Tesfay, 2013). Emaciation and cachexia also represent a welfare concern

89 in both humans and animals (Grandin, 2014).

90 Causes of emaciation are diverse and multifactorial, and generally rooted in either insufficient

91 intake/absorption and or losses of nutrients and energy than is being replaced. Haematological

92 evaluations have long been used as a reliable indicator of the physiological and health status of

93 farm animals (Etim et al., 2014). Oxidative stress (OS), the imbalance in levels of oxidants

94 (radicals or non-radicals) and antioxidants in favour of oxidants, in a biological system that triggers

95 oxidation of biomolecules such as proteins, lipids and DNA that results in cellular, tissue and organ

96 damage, have been implicated in the pathogenesis of several diseases of ruminants (Celi, 2011;

97 Lahera et al., 2006).

98 There are substantial evidence that OS is also a significant player in metabolic disorders induced

99 by obesity, overweight or high body condition scores (Bernabucci et al., 2005; Bayomi et al.,

100 2017). The role of OS in anemia has been reported (Salem et al., 2016). Essentially, OS induced

101 injury to circulating erythrocytes (damage to cell membrane leading to leakage and scrambling)

102 resulting in suicidal death or eryptosis, thereby causing to anemia (Bissinger et al., 2019). 
103 The WFC breed represents the largest population of cattle types in Nigeria which are raised mainly

104 for milk production (although yields are relatively poor) and beef under a predominantly nomadic

105 (extensive) system (Kubkomawa, 2017). During the dry season, emaciation is highly prevalent in

106 this breed, as animals are trekked over long distances in search of food and water. Haematological

107 disturbances, notably anemia is also a common feature due to presence of physical, environmental

108 and pathogen stressors coupled with various forms of nutritional deficiencies.

109 Although emaciation, OS and anaemia are fairly frequent characteristics in these animals, the

110 relationships between these disorders have not been well explored in WFC. Moreover, studies on

111 OS roles in ruminant health and disease is a relatively new area and sparse cognate reports are

112 available on these species in the study region. An understanding of the relationship and interactions

113 between these pathologic processes, could provide an important guide for improved management

114 and recovery protocols of EC, leading to better prognosis and quicker treatment outcomes.

115 The purpose of this study was, therefore, to determine the values of haematological parameters

116 and serum redox dynamics, including serum proteins, electrolytes and trace elements in emaciated

117 pre-slaughter WFC, compared to NEC, so as to determine optimum therapies that can be given to

118 pre-slaughter EC to improve their body condition and carcass quality prior to slaughtering. 


\section{Study animals}

122 Cattle were transported from the Northern part of Nigeria to be used for human food, and kept in 123 a pre-slaughter holding pen at the Lafenwa Central Abattoir, Abeokuta, (Coordinates; Latitude: $7^{\circ}$ 124 09' 23.40" N and Longitude: $3^{\circ} 20^{\prime} 32.40^{\prime \prime}$ E), Ogun State, Southwest Nigeria. Duration from time 125 of arrival time to time of slaughter usually ranges from 3 to 7 days. A group of emaciated $(n=37)$ 126 and non-emaciated $(\mathrm{n}=37)$ cows were purposively sampled from these group animals. Consent

127 was obtained from the abattoir authorities under the auspices of the Veterinary Services Division 128 of the Ogun State Ministry of Agriculture, and individual owners of the cows for the animal studies 129 and sample collection. Sampled cows had a score of 1 and 3 on a body condition scale of 1 to 5 130 (with 1 being severely emaciated, 3 - good body condition and 5 - obese.

\section{Sample Collection}

132 Approximately $8 \mathrm{ml}$ of blood was collected from the jugular vein into both heparinized and plain 133 bottles from each animal for hematological and biochemical analyses respectively. The samples 134 were stored on ice park and immediately transported to the laboratory for analysis. Serum was 135 harvested from blood and stored at $-20^{\circ} \mathrm{C}$ until analyzed.

\section{Haematology}

137 The packed cell volume (PCV, \%) and haemoglobin concentration (g/dl) were determined using

138 the microhaematocrit and cyanomethaemoglobin methods as described by Lepherd et al. (2009) 139 and Srivastava et al. (2014) respectively. The total white blood cells (WBC) and differential white 140 blood cell counts (neutrophils, lymphocytes, eosinophils, monocytes and basophils) $\left(\times 10^{9} / \mathrm{L}\right)$ and 
141 erythrocyte $\left(\times 10^{12} / \mathrm{L}\right)$ counts were evaluated by haemocytometry (Bain et al., 2016). Erythrocytic

142 indices including mean cell volume (MCV) (fl), mean corpuscular haemoglobin concentration

143 (MCHC) $(\mathrm{g} / \mathrm{dl})$ and mean corpuscular haemoglobin $(\mathrm{MCH})(\mathrm{pg})$ were determined by calculations

144 (Latimer, 2011).

\section{Serum Analysis}

147 Serum concentration of malondialdehyde (MDA) was determined according to the method of 148 Buege \& Aust (1978) as described by Gasso et al. (2016). The antioxidant reduced glutathione

149 (GSH) was measured by a colorimetric method described in Tian et al. (2010). Antioxidant 150 enzymes: catalase, superoxide dismutase (SOD) and glutathione -S- transferase (GST) activities 151 in the serum were assayed according to the methods of Shangari and O'Brien (2006), Marklund \& 152 Marklund (1974) and Habig et al. (1974) respectively, as described by Bauché et al. (1994).

153 Ascorbate (vitamin C) and tocopherol (vitamin E) concentrations were determined by colorimetric 154 and spectrophotometric techniques respectively, using a Randox ${ }^{\circledR}$ Ascorbate kit and as described 155 by Rutkowski and Grzegorczyk (2007). Trace elements in serum including copper, iron, selenium 156 and zinc, were evaluated by atomic absorption spectroscopy (AAS) (Atomic absorption 157 spectrometer, Shimadzu Asc-6100, Japan) as described by Kubaszewski et al. (2014). 158 Electrolytes: sodium, potassium and chloride were measured by spectrophotometry using the 159 respective $\mathrm{Teco}^{\circledR}$ diagnostic kits. Total protein and albumin were determined using Randox ${ }^{\circledR}$ kits, 160 while globulin concentration and albumin/globulin (A:G) ratio was calculated by substracting 161 albumin concentration from total protein values and ratio between albumin and globulin 162 concnetrations, respectively. 


\section{Data Analysis}

164 Continuous variables were presented as means and standard deviations. Tests for normality of data 165 distribution was performed using the Kolmogorov-Smirnov and Shapiro-Wilk tests. Comparisons

166 between indices in emaciated versus good body condition animals were carried out using

167 independent samples Student's T-test. Differences were considered significant at $\mathrm{P}<0.05$. All

168 statistical analyses were performed using the Statistical Package for Social Sciences (SPSS)

169 software, version 23.0 (SPSS Inc., Chicago, IL, USA).

170

171 


\section{Results}

173 Sampled cattle were aged two to six years, with a mean of 3.25 years. A few of the cows had minor

174 bruises, branding marks and a small number of ticks, most were apparently healthy except for

175 emaciation and signs of dehydration such as sunken eyes.

176 Haematology, Oxidative stress, Trace elements and electrolytes in Emaciated Cows

177 The results of the complete blood counts (mean \pm standard deviation) carried out on the blood

178 samples from both EC and NEC and the significance (p-value) levels are shown in Table 1. All

179 values (for both groups) fell within the haematology reference range for cattle (Jackson et al.,

180 2007), except the mean corpuscular haemoglobin (MCH) which was slightly higher than reference

181 range in both groups.

182 Table 1: Haematological parameters of emaciated $(n=37)$ versus non-emaciated cattle $(n=$ 183 37) (mean \pm standard deviation)

\begin{tabular}{|c|c|c|c|}
\hline Parameters & Emaciated & Non-emaciated & P-value \\
\hline PCV (\%) & $39.62 \pm 8.34$ & $41.22 \pm 6.43$ & 0.360 \\
\hline Hb (g/dl) & $12.31 \pm 1.55$ & $12.33 \pm 1.58$ & 0.953 \\
\hline $\mathrm{RBC}\left(\times 10^{12} / \mathrm{L}\right)$ & $6.91 \pm 1.21$ & $6.93 \pm 1.09$ & 0.928 \\
\hline $\operatorname{MCV}$ (fl) & $58.59 \pm 8.39$ & $59.88 \pm 7.14$ & 0.210 \\
\hline MCH (pg) & $18.09 \pm 2.36$ & $18.03 \pm 2.49$ & 0.917 \\
\hline $\operatorname{MCHC~(g/dl)~}$ & $31.81 \pm 4.73$ & $30.24 \pm 3.52$ & 0.108 \\
\hline WBC $\left(\times 10^{9} / \mathrm{L}\right)$ & $9.95 \pm 1.68$ & $9.97 \pm 1.60$ & 0.949 \\
\hline Neutrophil $\left(\times 10^{9} / L\right)$ & $2.87 \pm 0.48$ & $2.83 \pm 0.39$ & 0.696 \\
\hline Lymphocytes (x 109/L) & $6.65 \pm 1.19$ & $6.69 \pm 1.23$ & 0.883 \\
\hline Eosinophils (x 109/L) & $0.14 \pm 0.08$ & $0.18 \pm 0.09$ & 0.110 \\
\hline Basophils (x 10/L) & $0.13 \pm 0.07$ & $0.12 \pm 0.07$ & 0.574 \\
\hline Monocytes $\left(x 1^{9} / \mathrm{L}\right)$ & $0.16 \pm 0.09$ & $0.16 \pm 0.09$ & 0.899 \\
\hline
\end{tabular}


185 Mean and standard deviation values of the OS indicator and antioxidant compounds in EC and

186 NEC as well as p values showing statistical significance are displayed in Table 2. Values of GSH 187 were significantly lower in EC.

190 versus non-emaciated $(\mathbf{n}=\mathbf{3 0})$ cows.

\begin{tabular}{|c|c|c|c|}
\hline Parameters & Emaciated & Non-emaciated & P-value \\
\hline $\operatorname{MDA}\left(\mathrm{U} / \mathrm{L} \times 10^{-9}\right)$ & $3.85 \pm 2.85$ & $4.51 \pm 2.72$ & 0.331 \\
\hline Catalase (U/L) & $1.97 \pm 0.88$ & $2.14 \pm 0.89$ & 0.432 \\
\hline SOD (U/L) & $0.0085 \pm 0.0015$ & $0.009 \pm 0.0012$ & 0.127 \\
\hline GSH (U/L) & $236.65 \pm 23.53$ & $249.95 \pm 1.82$ & $0.03^{*}$ \\
\hline GST (U/L) & $0.021 \pm 0.017$ & $0.016 \pm 0.009$ & 0.114 \\
\hline Vitamin E $(\mu \mathrm{g} / \mathrm{ml})$ & $10.29 \pm 1.28$ & $10.18 \pm 1.50$ & 0.730 \\
\hline Vitamin C (mg/dl) & $3.73 \pm 0.88$ & $4.06 \pm 0.77$ & 0.105 \\
\hline
\end{tabular}

194 The results of serum electrolytes and trace elements (mean \pm standard deviation) as well as $\mathrm{p}$ values 195 showing statistical significance between EC and NEC cattle are depicted in Table 3. 
197 Table 3: Serum electrolytes and trace elements in emaciated $(n=30)$ versus non-emaciated $198 \quad(\mathbf{n}=\mathbf{3 0})$ cows $($ mean \pm SD)

\begin{tabular}{llll}
\hline Parameters & Emaciated & Non-emaciated & P-values \\
\hline Sodium $(\mathbf{m E q} / \mathbf{L})$ & $109.69 \pm 9.05$ & $109.95 \pm 8.40$ & 0.902 \\
Potassium $(\mathbf{m E q} / \mathbf{L})$ & $5.93 \pm 1.37$ & $5.61 \pm 2.23$ & 0.466 \\
Chloride $(\mathbf{m E q} / \mathbf{L})$ & $85.53 \pm 15.82$ & $86.91 \pm 15.62$ & 0.720 \\
Copper $(\boldsymbol{\mu g} / \mathbf{m l})$ & $0.45 \pm 0.18$ & $0.55 \pm 0.19$ & $0.032^{*}$ \\
Zinc $(\boldsymbol{\mu g} / \mathbf{m l})$ & $1.02 \pm 0.39$ & $1.07 \pm 0.23$ & 0.530 \\
Iron $(\boldsymbol{\mu g} / \mathbf{m l})$ & $1.92 \pm 0.51$ & $2.10 \pm 0.51$ & 0.147 \\
Selenium $(\boldsymbol{\mu g} / \mathbf{m l})$ & $0.23 \pm 0.12$ & $0.19 \pm 0.09$ & 0.116 \\
\hline
\end{tabular}

200 Serum Total Proteins

201 Serum protein profile in both EC versus NEC (mean \pm standard deviation) along with $p$ values are

202 shown in Table 4.

203 Table 4: Serum protein in emaciated $(n=30)$ versus non-emaciated $(n=30)$ cows

\begin{tabular}{llll}
\hline Parameters & Emaciated cattle & Non-emaciated & P values \\
\hline Total protein (g/dl) & $7.88 \pm 0.43$ & $8.02 \pm 0.48$ & 0.199 \\
Albumin (g/dl) & $4.20 \pm 0.33$ & $4.20 \pm 0.27$ & 0.897 \\
Globulin (g/dl) & $3.66 \pm 0.36$ & $3.81 \pm 0.32$ & 0.094 \\
A:G ration & $1.14 \pm 0.92$ & $1.10 \pm 0.84$ & 0.160 \\
\hline
\end{tabular}

204

205 


\section{DISCUSSION}

208 The present study has revealed the variations in haematological parameters, an OS marker, some

209 enzymatic and non-enzymatic antioxidants, trace elements, electrolytes and protein profiles of

210 serum in EC and non-emaciated pre-slaughter WFC.

211 Several studies have reported significant associations between anaemia (Igbokwe and Igbokwe,

212 2012; Akhaine et al., 2021), as well as leukopenia (Sivajothi et al., 2015) and leukocytosis

213 (Langenmayer et al., 2015; Ihedioha and Udeani, 2017) and emaciation. The variable relationship

214 between emaciation and parameters indicative of anemia specifically the PCV, may be influenced

215 by the presence of other homeostatic perturbations such as dehydration, which could present a

216 spurious increase in PCV (above reference range of 46\%) as observed in some animals sampled in

217 this study. The feed and water restriction, and exposure to high ambient temperature, overcrowding

218 and stress causing diarrheas and nasal discharge associated with transport of cattle over long

219 distances is a key factor that could precipitate dehydration (Rakib et al., 2016). In this study, signs

220 of dehydration, mainly sunken eyes and tenting of the skin, were observed more in the emaciated

221 cows. In addition, pre-slaughter animals frequently undergo prolonged duration (up to 24 to 72

222 hours) without feed and water even in pre-slaughter pens (Personal comm., ; Jarvis et al., 1996;

223 Alam et al., 2010; Rakib et al., 2016). As animals examined in the present study were recently

224 transported, our findings on the haematology agree closely with findings of Rakib et al. (2016)

225 who found elevated levels of PCV and $\mathrm{Hb}$ in recently transported cattle intended for slaughter,

226 these values were pointers to dehydration. Furthermore, from this study, RBC counts did not

227 exceed the reference range, therefore it could be concluded that the above-reference-range PCVs

228 seen in $17 \%$ of cows (with $53 \%$ of these, EC) was not due to polycythemia or even erythrocytosis

229 of splenic contraction. 
230 Previous reports have shown a strong association between emaciation and anemia (Igbokwe et al.,

231 2012), who found almost $37 \%$ of sampled emaciated animals to have anemia and even in non-

232 emaciated animals, so the results from the present study, where no animal (including emaciated)

233 had anemia (PCV below 24\%) was a deviation. This discrepancy may be due to various degrees

234 of dehydration in sampled animals which confounded the detection of anemia (Atata et al., 2018).

235 It is probable that the observation of slightly higher hematocrit in EC than the NEC, may be due

236 to pre-existing anemia in some of the cattle of both groups which was masked by dehydration.

237 White Fulani cattle in good condition have been reported to have higher PCV and lower neutrophil

238 counts compared to a group of cachectic cattle, although the difference was not statistically

239 significant (Aliyu et al., 2017). Our results from the present study collaborate this finding.

240 Contrary to the report of Aro (2019), who observed pre-slaughter leukocytosis due to monocytosis

241 in cattle, we did not observe abnormal values in the leucocyte-parameters in either EC or NEC.

242 The slightly higher concentration of the oxidant MDA, in the good condition cows, is a weak

243 indicator of an enhanced oxidative stress level in this group compared to the EC group. Previous

244 reports have shown positive relationships between good body condition and OS (Sordillo, 2013;

245 Bayomi et al., 2017; Gheise et al., 2017). This study's finding on the MDA seems to support their 246 observations.

247 However, antioxidants (SOD, catalase and vitamin C and the trace element zinc) were also slightly

248 higher in NEC, thereby contradicting the MDA pro-oxidant pointer. Furthermore, values of GSH

249 and copper (also involved in the antioxidant defense) which were significantly $(\mathrm{p}<0.05)$ higher

250 in NEC, favour the opposing opinion that the NEC, had a better redox balance than EC. Only GST,

251 vitamin $\mathrm{E}$ and selenium were slightly higher in EC than in NEC ones, and OS is also reported to 
252 be involved in the process of cachexia (an advanced stage of emaciation) (Ábrigo et al., 2018).

253 Therefore, further studies (under more controlled conditions) to ascertain if emaciation with or

254 without dehydration induces greater oxidative stress than obesity, is warranted.

255 It has been reported that underfeeding in cattle (which is a major cause of emaciation) results in

256 significant depletion of antioxidants (Sansinanea et al., 2000), so the ratio of some antioxidants in

257 EC relative to the non-emaciated cows observed in this study may be due to the greater demand

258 for nutrients (for example, amino acids required for synthesis of GSH, $\mathrm{Cu}$ and Fe required for other

259 non-antioxidant biosynthetic pathways in the body), in this group. Therefore, the lower PCV, $\mathrm{Cu}$,

$260 \mathrm{GSH}$ and Fe in emaciated than in non-emaciated animals may be mirroring the general effect of

261 reduction of nutrients in the body.

262 Moreover, dehydration occurs frequently with emaciation (and can also lead to emaciation) and

263 has been shown to increase OS (França et al., 2007) especially in transported cattle (Knowles,

264 1999). It can therefore be speculated that findings that implicate a tendency towards a pro-oxidant

265 status in EC, may have been contributed by dehydration which was more commonly noticed

266 (although not graded) among the EC in this study.

267 Of the serum electrolytes recorded in this study, the mean $\mathrm{Na}$ and $\mathrm{Cl}$ values were lower in both 268 groups while the mean $\mathrm{K}$ value was higher than that reported by Olayemi et al. (2001). Sodium 269 and $\mathrm{Cl}$ were recorded in the present study were slightly lower, while $\mathrm{K}$, slightly higher in EC. Loss 270 of electrolytes in the extracellular fluid along with water in the dehydration process is possible 271 explanation for this occurrence.

272 The mean total protein values in this study were close to range reported by Olayemi et al. (2001)

273 in extensively raised White Fulani cattle, but lower than in intensively raised ones, probably 
274 resulting from reduced nutrient intake. A higher proportion of chronically emaciated cows in the

275 study of Akhaine et al. (2021) also displayed hypoproteinemia mainly due hypoalbuminemia.

276 The values of $\mathrm{Fe}, \mathrm{Cu}$ and $\mathrm{Na}$ were higher in this study than ranges reported by Asif et al. (1996),

277 for cattle in different physiological states. The observation that $\mathrm{Fe}$ was slightly higher and $\mathrm{Cu}$,

278 significantly higher in the NEC group, may be related to the depletion from higher demand for Fe

279 and $\mathrm{Cu}$ in the EC. Also, the need for these elements to be recruited into several other biological

280 processes, for example erythropoiesis, aside from just the antioxidant system, in EC (Mishra et al.,

281 2019). A delicate balance of Fe is required to prevent OS as either deficiencies or excesses have

282 been shown to precipitate the production of free radicals (Knutson et al., 2000).

283 In conclusion, EC and non-emaciated pre-slaughter WFC showed minor differences in

284 haematology, oxidant/antioxidants, protein and trace elements patterns. Both groups of cows can

285 be said to be prone to oxidative stress as dehydration and depletion of antioxidants may contribute

286 to upsetting the redox homeostasis in favour of pro-oxidation in emaciated cows, while the higher

287 the body condition, has been related to enhanced OS in cattle as revealed by several studies (Gheise

288 et al., 2017; Laubenthal et al., 2017) and results of MDA in the present study. Therefore, in

289 addition to identifying and correcting the primary cause of emaciation in cattle intended for food,

290 guided antioxidant and trace elements supplementation is recommended, during fattening of cattle

291 for better market value. This is necessary to reduce the risks of OS and its associated complications, 292 and the long run effect on carcass and meat quality. 


\section{Acknowledgements}

296 Authors acknowledge Dr Tayo Ogunyeye, Dr Aisha Onatunde and other adhoc members of staff

297 at the Lafenwa Abattoir for their support during sampling, and Prof E. B. Otesile for critically

298 reviewing this manuscript.

299 


\section{References}

301 Ábrigo, J., Elorza, A.A., Riedel, C.A., Vilos, C., Simon, F., Cabrera, D., Estrada, L., Cabello302 Verrugio, C. and 1Departamento, 2018. Role of Oxidative Stress as Key Regulator of Muscle Wasting during Cachexia Oxidative Medicine and Cellular Longevity, 2018, 17

Akhaine, S., Taiwo, J.O. and Akanni, A.S., 2021. The trend of aetiologies of chronic emaciation in off-take cattle in Ibadan metropolis Journal of Veterinary Medicine and Animal Health,

Alam, M., Gregory, N., Jabbar, M., Uddin, M., Widdicombe, J., Kibria, A., Khan, M. and Mannan, 13, 1-14 (Academic Journals)

Aliyu, A., Natala, A.J., Adamu, S., Igbokwe, I.O., Esievo, K.A.N. and Useh, N.M., 2017. A A., 2010. Frequency of dehydration and metabolic depletion in cattle and water buffalo transported from India to a livestock market in Bangladesh Animal Welfare, 19, 301-305

Aro, S.O., 2019. Haematological study of a composite cattle population reflects pre-slaughtercomparative study on the haematology, biochemical alterations in serum composition and pathological changes in the kidneys of cachetic and non-cachectic cattle in Zaria, Nigeria. International Journal of Biochemistry Research and Review, 19, 1-11

Asif, M.M., Zia-Uur-Rahman, Arif, M., Haq, I.U. and Javed, I., 1996. Trace Element and induced breed and sex differences Nigerian Journal of Animal Science, 21, 17-29

Assefa, A. and Tesfay, H., 2013. Major causes of organ condemnation and economic loss in cattle slaughtered at adigrat municipal abattoir, northern ethiopia Veterinary World, 6, 734-738 
321 Atata, J.A., Esievo, K.A.N., Adamu, S., Abdulsalam, H., Adam, M. and Chiroma, M.A., 2018. 322 Haematological and biochemical parameters of clinically dehydrated and euhydrated dogs 323 Sokoto Journal of Veterinary Sciences, 16, 73-78

324 Bain, B., Bates, I. and Laffan, M., 2016. Dacie and Lewis Practical Haematology E-Book: Expert 325 Consult: Online and Print,

326 Bauché, F., Fouchard, M., Letters, B.J.-F. and 1994, U., 1994. Antioxidant system in rat testicular cells FEBS Letters, 349, 392-396

Bayomi, Y.H., Mohamed, W.A.M. and Morsi, A.K.M., 2017. Oxidative Stress Biomarkers in Dystrophic Lambs and Kids in Relation to Body Condition Scores Zagazig Veterinary Journa, $45,189-200$

Bernabucci, U., Ronchi, B., Lacetera, N. and Nardone, A., 2005. Influence of body condition score on relationships between metabolic status and oxidative stress in periparturient dairy cows Journal of Dairy Science, 88, 2017-2026 (American Dairy Science Association)

Bissinger, R., Bhuyan, A.A.M., Qadri, S.M. and Lang, F., 2019. Oxidative stress, eryptosis and anemia: a pivotal mechanistic nexus in systemic diseases The FEBS Journal, 286, 826-854 (Blackwell Publishing Ltd)

337 Celi, P., 2011. Biomarkers of oxidative stress in ruminant medicine Immunopharmacology and 338 Immunotoxicology, 33, 233-240

339 Etim, N.N., Williams, M.E., Akpabio, U. and Offiong, E.A., 2014. Haematological Parameters and Factors Affecting Their Values Agricultural Science, 2, 37-47

341 França, M.B., Panek, A.D. and Eleutherio, E.C.A., 2007. Oxidative stress and its effects during 
dehydration Comparative Biochemistry and Physiology - A Molecular and Integrative Physiology, 146, 621-631 (Elsevier Inc.)

344 Gasso, D., Vicente, J., Mentaberre, G., Soriguer, R., Rodrıguez, R.J., Nora, N., Tvarijonaviciute, 345 A., Lavin, S., Pedro Fernandez-Llario, J.S. and Emmanuel Serrano, 2016. Oxidative Stress in 346 Wild Boars Naturally and Experimentally Infected with Mycobacterium bovis PLoS ONE, $347 \quad 11,1-17$

348 Gheise, N.J.E., Riasi, A., Shahneh, A.Z. and Celi, P., 2017. Effect of pre-calving body condition 349 score and previous lactation on BCS change, blood metabolites, oxidative stress and milk 350 production in Holstein dairy cows Italian Journal of Animal Science, 16, 474-483

351 Grandin, T., 2014. Animal welfare and society concerns finding the missing link Meat Science, $352 \quad 98,461-469$ (Elsevier Ltd)

353 Igbokwe, I.O. and Igbokwe, N.A., 2012. Abstract Book , doi: 10.13140/2.1.1887.6809

354 Ihedioha, J.I. and Udeani, I.J.C.K., 2017. Hematological and serum biochemical alterations in 355 White Fulani cattle with tuberculous lesions Rev. Elev. Med. Vet. Pays Trop., 70, 127-130

356 Jackson, P.G.G., Cockcroft, P.D. and Medicine, K.W.V., 2007. Appendix 2: Laboratory Reference 357 Values: Haematology,

358 Jarvis, A., Harrington, D. and Cockram, M., 1996. Effect of source and lairage on some 359 behavioural and biochemical measurements of feed restriction and dehydration in cattle at a 360 slaughterhouse Applied Animal Behaviour Science, 50, 83-94

361 Kambarage, M., Kimera, S.I., Kazwala, R.R. and Mafwere, B.M., 1995. Disease conditions 362 responsible for condemnation of carcasses and organs in short-horn Zebu cattle slaughtered 
364 Knowles, T.G., 1999. A review of the road transport of cattle Veterinary Record, 144, 197-201 365 (British Veterinary Association)

366 Knutson, M.D., Walter, P.B., Ames, B.N. and Viteri, F.E., 2000. Both iron deficiency and daily 367 iron supplements increase lipid peroxidation in rats Nutrient Interactions and Toxicity, 130, 368 621-628 (American Institute of Nutrition)

369 Kubaszewski, Ł., Zioła-Frankowska, A., Frankowski, M., Nowakowski, A., Czabak-Garbacz, R., 370 Kaczmarczyk, J. and Gasik, R., 2014. Atomic absorption spectrometry analysis of trace elements in degenerated intervertebral disc tissue Medical Science Monitor, 20, 2157-2164

Kubkomawa, H.I., 2017. Indigenous Breeds of Cattle , their Productivity, Economic and Cultural Values in Sub-Saharan Africa: A Review nternational Journal of Research Studies in

Lahera, V., Goicoechea, M., De Vinuesa, S.G., Oubiña, P., Cachofeiro, V., Gómez-Campderá, F., Amann, R. and Luño, J., 2006. Oxidative stress in uremia: The role of anemia correction In:, Journal of the American Society of Nephrology,

Langenmayer, M.C., Scharr, J.C., Sauter-Louis, C., Schares, G. and Gollnick, N.S., 2015. Natural Besnoitia besnoiti infections in cattle: Hematological alterations and changes in serum chemistry and enzyme activities BMC Veterinary Research, 11 (BioMed Central Ltd.) Edition, Fifth Edit K. S. Latimer. (ed), (A John Wiley \& Sons, Inc., Publication: 1. Latimer KS. Duncan and Prasse's Veterinary Laboratory Medicine Clinical Pathology 5th Edition. 
Fifth Edit. Latimer. KS, editor. A John Wiley \& Sons, Inc., Publication;)

385 Laubenthal, L., Ruda, L., Sultana, N., Winkler, J., Rehage, J., Meyer, U., Dänicke, S. and 386 Sauerwein, H., 2017. Effect of increasing body condition on oxidative stress and 387 mitochondrial biogenesis in subcutaneous adipose tissue depot of nonlactating dairy cows 388 Journal of Dairy Science, 100, 4976-4986 (American Dairy Science Association)

Lepherd, M.L., Canfield, P.J., Hunt, G.B. and Bosward, K.L., 2009. Haematological, biochemical and selected acute phase protein reference intervals for weaned female Merino lambs. Australian Veterinary Journal, 87, 5-11

Mesele, G., Guadu, T., Bogale, B. and Chanie, M., 2012. Pathological Conditions Causing Organ and Carcass Condemnation and Their Financial Losses in Cattle Slaughtered in Gondar ,

Mishra, A., Shukla, D. and Saraf, M., 2019. Copper: Its Biological Role and Toxicity Journal of Northwest Ethiopia African Journal of Basic and Applied Sciences, doi: 10.5829/idosi.ajbas.2012.4.6.66146 the Indian Botanical Society, 98, 26-36

Olayemi, F.O., Oyewale, J.O. and Fajinmi, J.L., 2001. Plasma electrolyte, protein and metabolite levels in Nigerian White Fulani cattle under two different management systems Tropical Animal Health and Production, 33, 407-411

Pełczyńska, E., 1987. [Effects of leanness and emaciation of cattle on quantitative characteristics of meat]. Polskie archiwum weterynaryjne, 24, 515-28

Phiri, A.M., 2006. Common conditions leading to cattle carcass and offal condemnations at 3 
Raji, M.A., Salami, S.O. and Ameh, J.A., 2010. Pathological conditions and lesions observed in slaughtered cattle in Zaria abattoir,

Rakib, T.M., Hassan, M.M., Faruq, A. Al, Erfan, R., Barua, S.R., Faruk, M.O., Hasanuzzaman, M., Chowdhury, S. and Alam, M., 2016. Effect of Transport on Physical and Haematological

Rutkowski, M. and Grzegorczyk, K., 2007. Modifications of Spectrophotometric Methods for Antioxidative Vitamins Determination Convenient in Analytic Practice,

Salem, N.Y., Yehia, S.G., Farag, H.S. and Elkhiat, M.A., 2016. Clinical, hemato-biochemical Status of Cattle in Bangladesh Journal of Animal Health and Production, 4, 78-86

Sansinanea, A., Cerone, S., Virkel, G., Streitenberger, S., Garcia, M. and Auza, N., 2000. alterations and oxidant-antioxidant biomarkers in Babesia -infected calves International Journal of Veterinary Science and Medicine, 4, 17-22

Shangari, N. and O’Brien, P.J., 2006. Catalase Activity Assays Current Protocols in Toxicology, Nutritional Condition Affects the Hepatic Antioxidant Systems in Steers Veterinary Research

Sivajothi, S., Rayulu, V.C. and Sudhakara Reddy, B., 2015. Haematological and biochemical 27, 7.7.1-7.7.16 (John Wiley \& Sons, Ltd)

424 Sordillo, L.M., 2013. Selenium-dependent regulation of oxidative stress and immunity in 425 periparturient dairy cattle. Veterinary medicine international, 2013, 154045 (Hindawi) 
426 Srivastava, T., Negandhi, H., Neogi, S., ... J.S.-J.H. and 2014, U., 2014. Methods for hemoglobin 427 estimation: A review of" what works Journal of Hematology \& Transfusion, 2, 1028

428 Tian, Y., Jiang, W., Gao, N., Zhang, J., Chen, W., Fan, D., Zhou, D. and An, J., 2010. Biochemical 429 and Biophysical Research Communications Inhibitory effects of glutathione on dengue virus 430 production Biochemical and Biophysical Research Communications, 397, 420-424 (Elsevier $431 \quad$ Inc.)

432 